\title{
Culture Shock Re-Visited: What Features Of The Polish Culture Most Bother Expatriates In Poland?
}

Anna Murdoch, Ph.D., Warsaw School of Economics, Poland Eugene Kaciak, Ph.D., Brock University, Canada

\begin{abstract}
This paper investigates how symptoms of culture shock may be related to cultural features. A group of expatriate executives are tested on how they respond to Poland's culture dimensions which are specified in accordance with Hofstede's indices. Symptoms of their culture shock are identified and juxtaposed with everyday behaviours of Poles in the workplace and public place/social arena. The results show that some of those functional patterns of Poles which result in extreme/inefficient/counterproductive behaviours and constitute sources of culture shock for the expatriates are linked to large Power Distance and strong Uncertainty Avoidance in Poland or a combination of the two dimensions. Implications for researchers are specified. Recommendations for expatriate managers vis-à-vis induction training and the content of in-company courses for Polish managers are listed.
\end{abstract}

Keywords: culture shock; Hofstede's cultural dimensions framework; expatriates in Poland; Power Distance; Uncertainty Avoidance

\section{INTRODUCTION - CULTURE SHOCK}

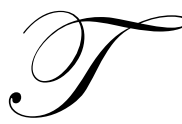

he phenomenon of culture shock as a concept was described as early as the 1950s (Lysgaard, 1955; Oberg, 1960). Sverre Lysgaard was commissioned by the United States Educational Foundation in Norway in 1955 to carry out a study on 198 Norwegian Fulbright students in the US. However, it was anthropologist Kalervo Oberg who first introduced the concept and gave it the name of "culture shock" in a seminar addressed to the Women's Club of Rio de Janeiro, Brazil, on August 3, 1954 although the text of his presentation did not appear in print until 1960 and thus it was preceded by Lysgaard's paper. Oberg referred to the symptom complex known as culture shock as: "an occupational disease of people who have been suddenly transplanted abroad" (p. 177). Oberg also inventoried the symptoms of culture shock, such as: "a feeling of helplessness (...) and fits of anger over delays and other minor frustrations" (p. 177). Additionally Oberg's contribution in the field was the description of the reasons for culture shock, such as losing the guidance of the familiar social cues; finding oneself in a sea of incomprehensible contextual signs; rejection of the host country and glorification of the home country (which Oberg calls "regression"). He also identified stages in the development of the process and gave them names, i.e. the honeymoon period, the hostility stage, the opening to the new cultural environment and acceptance to the point of enjoying the new country. Some of those terms have solidly entered the epistemology of the subject, e.g., the honeymoon period. Lysgaard's contribution as a founding father of the culture shock consisted of a proposition of a U-curve, i.e., a formal model to describe the unfolding of culture shock, which he described in the following way: [We] observed that adjustment as a process over time seems to follow a Ushaped curve: adjustment is felt to be easy and successful to begin with; then follows a 'crisis' in which one feels less well adjusted, somewhat lonely and unhappy; finally one begins to feel better adjusted again, becoming more integrated into the foreign community (Lysgaard 1955: 51). His other contribution has been the fact that his publication was based on formal research rather than - as in the case of Oberg's essay - on observation alone. 
Following the two pioneering publications, the idea of culture shock was integrated into a discussion about cultural adjustment. Since its conception, culture shock (and the adjustment process which accompanies it) had been researched as a "dizzying array of experiences collectively labeled as culture shock, adjustment, cross-cultural adaptation, or acculturation" (Sussman, 2000, p. 355). The notion of "acculturative stress" (Berry and Anis, 1974) ${ }^{\mathrm{i}}$ was transplanted from psychology into the body of research on culture shock related issues. Guy and Patton (1996) described "sojourner adjustment" as "an umbrella construct often interchanged with terms such as cross-cultural adaptation or adjustment and cultural assimilation" (p. 365). The earlier (1950s -1970s) stage of the research and epistemology concentrated on the description of the phases and the shape of the adjustment curve (Lysgaard, 1955; Gullahorn and Gullahorn, 1963). Later reviews of the U-curve literature done by scholars from different disciplines have found that there is weak empirical evidence to support the construct, at least in its more simplified definitions. For example, in 1982, Church reviewed empirical research on the U-curve. His evaluation was that evidence for the model was "weak, inconclusive and over-generalized" (p. 542). The W-curve model of cultural shock (Gullahorn and Gullahorn, 1963) was later followed by Kohls's work on Peace Corps volunteers (1984). Kohl contributed to the field the concept of the cyclical (not necessarily in the $\mathrm{W}$ shape but consisting of ups and downs) unfolding of the culture shock process. In 1986 Furnham and Bochner evaluated how aptly various theories can account for both subtle and complicated differences in responses of different groups to cultural shock. They listed the several theories that described a variety of factors, including locus of control, expectation (expectancy-value), negative life events, social support, and social-skills approaches.

Since the 80s, the major research effort focused on the creation and refinement of an adjustment framework as well as its operationalisation (as summarized by Sappinen, 1993) and the taxonomy of the cultural adjustment (Black and Mendenhall, 1990; Black and Mendenhall, 1991; Black, Mendenhall and Oddou, 1991; Sappinen, 1993; Shaffer, Harrison and Gilley, 1999; Haslberger and Brewster, 2005; Takeuchi, Wang and Marinova, 2005) while "adjustment is [still] a critical concept in the acculturation literature" (Aycan 1997, p. 436). The research was also stimulated by the contribution from human resources and expatriate literature (Mendenhall and Oddou, 1985; Mendenhall and Oddou, 1988; Tung 1981, 1982, 1987; Harzing, 1995; Birdseye and Hill, 1995) as well as from the field of cross-cultural training which called for the development of a cohesive 'adjustment system' and an ordered body of knowledge (Kohls and Knight, 1994; Littrell et al., 2006; Live and Work Abroad GMAC, 2001; Mendenhall and Oddou, 1986; Merta, Stringham and Ponterotto, 1988).

Since then culture shock has gained recognition as an important issue in cross-cultural studies and practice and as such has been incorporated into the pre-departure training programs both of expatriate executives and their families as for international exchange students (GMAC publications 2001 and 2004; Arthur, 2003; Clark, Oropeza $e t$ al, 1991; Crano and Crano, 1993; Chin, 2002).

\section{LITERATURE REVIEW}

Since it was terminologically born, culture shock has remained an interdisciplinary field. Culture shock and culture adjustment have been analyzed, dissected, discussed and described by academics from varied fields, such as psychology (Adler, 1975; Berry and Annis, 1974; Berry et al., 1987; Berry et al., 1992; Searle and Ward, 1990; Triandis and Heron, 1981; Sussman, 2000; Ward, Bochner and Furnham, 2001; Ward, Leong and Low, 2004), international business experts, researchers and practitioners in cross-cultural management (Kohls, 1984; Kohls and Knight, 1994; Merta et al., 1988; Ng, 2008; Novicevic and Harvey, 2001), short story editors (Lewis and Jungman, 1986; Dicks, 1993) as well as management consultants (Klos, 1996; Ten Years of Global Relocation Trends GMAC 2004). The interdisciplinary character of the field keeps drawing attention from young academics which is reflected in the abundance of recent doctoral theses as well as their quality (Bolino, 2000; Bolino and Feldman, 2000; Wang, 2003; Giuliani, 2004; Lin, 2007; Mol, 2007). It appears that the phenomenon will retain the interest of experts from the academia and practice alike as globalization keeps progressing and the needs of cross-cultural human capital are gaining more recognition.

Although culture shock is now an integral part of the "cultural adjustment" discussion and it is generally discussed with the coping techniques, we decided to subtract its essence from the wider body of knowledge for the purpose of this study. The rationale for this has been the idea to link an outsider's (i.e., somebody who is not embedded in the culture from birth) reaction to specific representations of the host culture, personified by cultural 
dimensions. Any outstanding (meaning higher than average, more intense than average, more consistent and more frequent) response would lead us to identify the feature of the host country that particularly jarred on the observers. The observers had to be foreigners, since they presented an unbiased (by socializing) view. The type of jarring reaction we chose is irritation, as it presents a type of immediate reaction. In order to "provoke" the identification of irritation we needed to prepare a list of various behaviors in a public and professional context (the division between the two is also further elaborated on). If one or more features (pervasive in the host country) could be identified we could then draw possible conclusions on how to incorporate this knowledge into the body of managerial and international student counseling (student induction) literature as well as manuals and training course syllabi. We have not encountered a similar approach in the existing literature. In particular, we have not encountered a study which would list a list of possible behaviors (of the locals) typical for a specific cultural dimension and how they can be interpreted by expatriates in the crisis stage of their culture shock. We have not encountered a systematic account of how cultural dimensions are translated into the routine functioning of the people in a country characterized by those dimensions and what reactions they can evoke in the foreigners who are having to function in this country. Therefore - by presenting this paper - we hope to be able to offer added value by pointing out this connection and possibly filling in the gap in the culture shock and expatriate literature. Additionally, we hope to draw attention to the issue of how certain countries (which are in a way exceptional in the sense that they represent a unique cluster of cultural features, as is the case of Poland) may find it harder to adjust to the accepted business norms, such as certain managerial practices (in which less Power Distance is encouraged as it opens avenues for constructive discussion and problem solving).

An eclectic definition (based on the definitions Oberg, 1960, Kohls, 1984 and Sappinen, 1993) of the bare concept is now presented and is followed by the description and justification of the methodology employed in this study. Afterwards, we present the discussion of the investigation's results as well as the closing remarks on the possible application of the study.

A phenomenon identified as culture shock is experienced by people who spend an extended period of time (usually more than three months) in a foreign country. This phenomenon takes the form (state) of stress (unfolding through a process) caused by the transition of an individual between culturally different environments. Culture shock is the result of confrontation with a culture different from one's own. Therefore, only people who must perform effectively within a foreign environment (e.g., while working or while their partner is working and/or while they and/or their partner is studying) are subject to the phenomenon. People who are posited in a foreign culture as transient and/or isolated bystanders (e.g., tourists) do not undergo the process.

Two important issues - especially in view of our study's design - need to be mentioned here: one is that culture shock adapts itself (through spreading or contracting) to the duration of time a person stays abroad, i.e., that irrespective of the length of stay, people will go through all the phases of the adjustment curve - either in an extended or compressed manner (Kohls, 1984, p. 67). We embraced this idea in our approach to treat the respondents in our study as having undergone or undergoing culture shock irrespective of the time frame, i.e., how long they have actually lived in the country we conducted the study in, i.e., Poland. The other aspect is perhaps less commonly recognized: research on culture shock and the acculturation process has shown that the extension of stay in a foreign country is not related to a constant decrease in acculturation problems or a constant increase in positive attitudes towards the foreign culture and population (Thomas, 1993, p. 386).

The symptoms and manifestations of culture shock have been reiterated in many works (Mendenhall and Oddou, 1986; Sappinen, 1993; Searle and Ward, 1990; Haslberger, 2005b; Leung et al., 2005; Littrel et al., 2006).

Sappinen (1993) listed the following symptoms of culture shock:

- $\quad$ feelings of anxiety, confusion, strain, embarrassment, disappointment, frustration, impatience, anger;

- $\quad$ loss of control and a loss of sense of mastery in a situation;

- $\quad$ physiological responses such as sleeplessness, stomach-aches, headaches, and trembling hands;

- $\quad$ fatigue, tension, excessive concern about hygiene, hostility, an obsession about being cheated, withdrawal into work, family, or the expatriate community or, in extreme cases, excessive use of drugs and alcohol;

- $\quad$ feeling of loss and deprivation; 
- $\quad$ feeling of being rejected by members of the new culture;

- $\quad$ confusion towards own role, values and identity;

- $\quad$ feeling of helplessness and inability to cope with the new environment (p. 4).

Clinical psychologists (Berry et al., 1987) described the symptoms caused by acculturative stressors in the following terms: "lowered mental health status (specifically confusion, anxiety, depression), feelings of marginality and alienation, heightened psychosomatic symptom level, and identity confusion. (p. 492). Takeuchi et al. (2005) summarized (with the support of specialist literature) the findings on the stressors as "negative psychological reactions (e.g., anxiety, frustration, anger), physiological problems (e.g., high blood pressure, coronary heart disease), and behavioral reactions (...)" (p. 927). The following characteristics consistently appear in all literature:

- $\quad$ lack of orientation, uneasiness and anxiety;

- $\quad$ psychological and physical problems (depression, stress, illnesses);

- $\quad$ feelings of helplessness and powerlessness;

- $\quad$ a lack of trust and self-confidence;

- $\quad$ defensive responses and (possible) withdrawal.

It is important to note that authors writing on culture shock tend to emphasize the universality of the phenomenon, i.e., that it will inevitably occur in anyone confronted effectively (i.e., having to cope with it) with a culture different from his/her own, although there is some literature to the contrary (Kealey, 1989).

\section{HYPOTHESES} hypothesis:

Based on the above, particularly in view of the often mentioned health problems, we propose our first

H1: Culture shock sufferers will fall prey to illnesses more frequently in the new environment than in their usual milieu.

Among the groups which tend to experience culture shock/adjustment are international exchange and international students. The very study which initiated the examination of the phenomenon (Lysgaard, 1955) was performed on student respondents. Since then international exchange students and international students (usually at university level) have been studied extensively and exhaustibly and referred to incessantly (Berry, Kim and Minde, 1987; Pandeliou and Craig, 2006; Lewthwaite, 1996; Ward, Leong and Low, 2004; Popadiuk and Arthur, 2004; Ang, van Dyne and Koh, 2006; Townsend and Wan, 2007). The studies which use international students for testing will, no doubt, keep emerging, as the number of international and international exchange students is rising. Of particular interest to us were the "student" studies that looked at the possible association between age and the extent of culture shock. However, they did not offer a confirmation of such an association. For example, the Pandeliou and Craig study (2006) stated that "no statistically significant relationship was detected between the age of the respondents and culture shock $(\mathrm{r}=.008, \mathrm{p}=0.925)$. The mean score of culture shock for women was higher $(8.34$; $\mathrm{sd}=3.7)$ than that for men $(6.56$; $\mathrm{sd}=3.7)$. This difference was statistically significant $(\mathrm{p}=0.007$, Pandeliou and Craig, 2006, p.779). Another interesting insight was proposed by Leithwaite (1996) although his (qualitative) study was based on a very small sample $(\mathrm{N}=12)$ of international graduate students in New Zealand. His conclusions indicate that the adjustment process of such students is not a particularly difficult experience. This view was confirmed by Townsend and Wan (2007) who investigated business students in the Asia Pacific Basin.

Following the conclusions from the above listed findings (and our own experience with international exchange students), we investigated a possible association between age and the extent of culture shock in our study as well, which we formulated as our second hypothesis:

H2: There is no association between the occurrence of physical illness and age. 
Our third and fourth hypotheses also relate to culture shock symptoms but those of psychological nature. These are reflected by feelings and as such are impossible to measure. We followed other researchers' insight in this area: "Emotions are difficult to measure. LeDoux (2002) emphasizes that direct measurement of emotions in humans encounters ethical and practical barriers. Rather than feelings, researchers measure behaviour or verbal reports of emotions" (Haslberger, 2005, p. 86). We followed this guideline.

Out of the array of possible psychological symptoms we chose irritation. Such an approach had antecedents in the literature, e.g., Gudykunst and Hammer (1988) who have combined uncertainty reduction with an affective dimension. They focused on the negative emotion of anxiety. In contradiction to their approach, we chose to target irritation, since it can be an immediate action reaction. In contradiction to such symptoms as, for example, "depression", "loss" and "anxiety", which cannot be associated with one particular incident, we decided to link the symptom of irritation with certain common behaviors encountered in the local environment. We "packaged" irritation in statements, which would reflect the respondents" irritation. In other words we "translated" irritation into statements about the locals' behavior (short, colloquial sentences usually beginning (or ending) with "It drives me crazy when..." or "I am tired with..." or "I can't stand..."). We got the idea of "translating" (expressing) feelings into short colloquial phrases from Berne (1964, pp. 66-67) who pointed out that nothing describes an emotional state more precisely and succinctly than a short, colloquial phrase.

Our second decision regarded the choice of areas that expatriates could be irritated with. Those areas had been identified, although for a different purpose. Black (1988), Black and Stephens (1989), and Black and Mendenhall (1990) proposed a three-fold split in the adjustment process: general adjustment, interaction adjustment, and work adjustment. We generally followed those guidelines but condensed the three into two areas of expatriates' activity: work place and community/social/public space in Poland. The reason we collapsed the three areas into two is that we decided to exclude such factors as the food, cost of living etc. (which are considered to belong into the area of general adjustment by Black and colleagues) since the cost of living is lower in Poland than in the countries represented by our respondents (with the exception of the respondent from Belarus) and would not therefore act as an "irritant".

The third step in the process of formulating Hypotheses 3 and 4 was to bisociate irritation with cultural dimensions. For this we undertook to juxtapose culture shock (as represented by irritation) with quantified cultural criteria. The framework of cultural dimensions set forth by Hofstede (1980) was chosen as it offers measurable cultural criteria ${ }^{\text {ii. }}$ The culture features listed by his model are unambiguously identifiable and measurable, and - in contradistinction to some other models, e.g., Schwartz's (1994) and GLOBE's (2004) - they have been applied in the existing empirical and theoretical cross-cultural research on Poland (Nasierowski and Mikula, 1998; Todeva, 1999; Kolman, Noorderhaven, Hofstede, and Dienes, 2003; Zdunczyk and Blenkinsopp, 2007; Murdoch, 2009). Most of those publications focus on managerial issues. Our study has some relevance vis-à-vis management in Poland. By using the same terms of reference in the cross-cultural area, i.e., the same cultural dimensions we could contribute to this budding field of research. Another reason for selecting Hofstede's grid of cultural dimensions is the fact that - at least on one occasion - it had been identified as useful in dealing with culture shock and adjustment difficulties. Deen (2002) recommends Hofstede's model for counsellors who help (young) clients suffering from sojourner adjustment difficulties: "... [b]ecause no counsellor can be knowledgeable about all cultures in the world, it is important to be aware of patterns as described by Hofstede (1990), and actively listen to what the client has to say" (p. 15).

We are not aware of any other studies in which culture shock would be directly confronted with Hofstede's cultural dimensions.

Geert Hofstede's research on culture was based on a large database of employee values collected by IBM between 1967 and 1973 covering more than 70 countries. The first report on 40 countries was published in 1980. In 1983, the analysis covered 50 countries and three regions. The sample included seven different levels of occupation, from managers to administrative personnel. Altogether there were more than 116,000 questionnaires in 20 languages. The survey instrument (the questionnaire) included 160 questions, of which 63, mainly pertaining to values, were used in the cross-cultural analysis. In the subsequent editions of Hofstede's works since 2001, scores are listed for 53 countries, and 3 regions (i.e., the Middle East and Northern Africa, called by Hofstede the "Arab 
World"; East Africa and West Africa). These scores are partly based on replications and extensions of the original IBM study.

In this paper, we have sourced the data for their calculations (as presented later in the paper) from the ITIM on-line research resource (http://www.geert-hofstede.com) - as retrieved in December 2007. The data (i.e., the scores) are from 2004 (as stated on the website). We have decided to include brief definitions of the cultural dimensions, as proposed by Hofstede. Individualism (IDV) focuses on the degree the society reinforces individual or collective achievement and interpersonal relationships. Power Distance Index (PDI) focuses on the degree of equality, or inequality, between people in the country's society. Masculinity (MAS) focuses on the degree the society reinforces, or does not reinforce, the traditional masculine work role model of male achievement, control, and power. Uncertainty Avoidance Index (UAI) focuses on the level of tolerance for uncertainty and ambiguity within the society, e.g., unstructured situations. Long Term Orientation was added later. It has been established only for 28 countries (regions). It is based on Confucian dynamism. Values associated with Long Term Orientation are thrift and perseverance; values associated with Short Term Orientation are respect for tradition, fulfilling social obligations, and protecting one's 'face'.

Hofstede's dimensions have been applied to test various aspects of performance on both macro and micro levels. His model has served many researchers to develop constructs to assess how well people perform in a foreign cultural set while being guided by their own culture. For example Gooden (2003) has identified that effective leaders' practices must be compatible with the values of the society in which they operate. Although we did not attempt to specify how the differing values might meet, thus - possibly - leading to easing the symptoms of culture shock while increasing efficacy, we were re-affirmed in the decision to choose Hofstede's framework as appropriate in building the rationale for our study.

The next step was to position the cultural dimensions of Power Distance, Individualism, Uncertainty Avoidance, Masculinity, and Long Term Orientation against the backdrop of the culture shock theory. The main premise was to "translate" the Hofstede framework to a scheme of (coded) statements pertaining to: 1) professional arena, 2) social/community/public space in Poland. In this study, it meant verbalizing irritation in 15 statements referring to workplace and 15 statements referring to public space - see Q3 and Q4 in the Attachment. The irritation would be directed at various aspects of the expatriate's life (which we coded as relating to PD, UA, MAS, IDV, LTO, correspondingly). We asked the respondents to state which one irritated them the most. The dimensions in Q 3 and 4 are not represented symmetrically by the corresponding number of statements - for the rationale see "Additional Assumptions".

The choice of the geographical setting for the experiment was primarily conditioned by the fact that Poland is, in fact, one of the very few countries which Hofstede identified as exceptions (other exceptions are: France, Belgium, Costa Rica). Poland has both a high Power Distance value (68) and a high Uncertainty Avoidance Index (93). Most Western countries have these two values negatively or weakly correlated (Hofstede, 1984, pp. 214 and 215). In the original work (Hofstede, 1980), the plotting of the 40 original countries on a PDI-versus-UAI axis created the lower right quadrant of the plot (large PD, strong UAI) which included a Latin plus Mediterranean cluster and, additionally, Japan (p. 214). Poland should be placed in a position pushed to the extreme right and extreme bottom of the quadrant. Hofstede indicates that in the countries where PDI is large, power is the leading principle (thus taking precedence over UAI) (p. 215). According to Hofstede, the organization type in such countries tends to represent the type of full bureaucracy, and the implicit model of organization is the pyramid. We have taken this assumption in the formulation of $\mathrm{H} 3$ and $\mathrm{H} 4$, speculating that Power Distance will be the most noticeable feature.

This somewhat unique feature makes Poland a very interesting object of investigation. Another interesting characteristics of Poland (along with other post-communist countries) is the fact that the whole nation may be undergoing a process of collective culture shock (Feichtinger and Fink, 1998), although there has been no - to our knowledge - empirical research which would confirm Feichtinger and Fink's hypothesis. Therefore this insight would be impossible to measure. However, it may lead to speculations that an expatriate's culture shock may indeed be experienced in a different manner (e.g., more acutely) in such a country. We think this particular issue may be an interesting avenue to research. 
Graphs 1 and 2 illustrate Hofstede's dimensions in a compact comparative way vis-à-vis Poland (Poland vs. the US, Europe and the World).

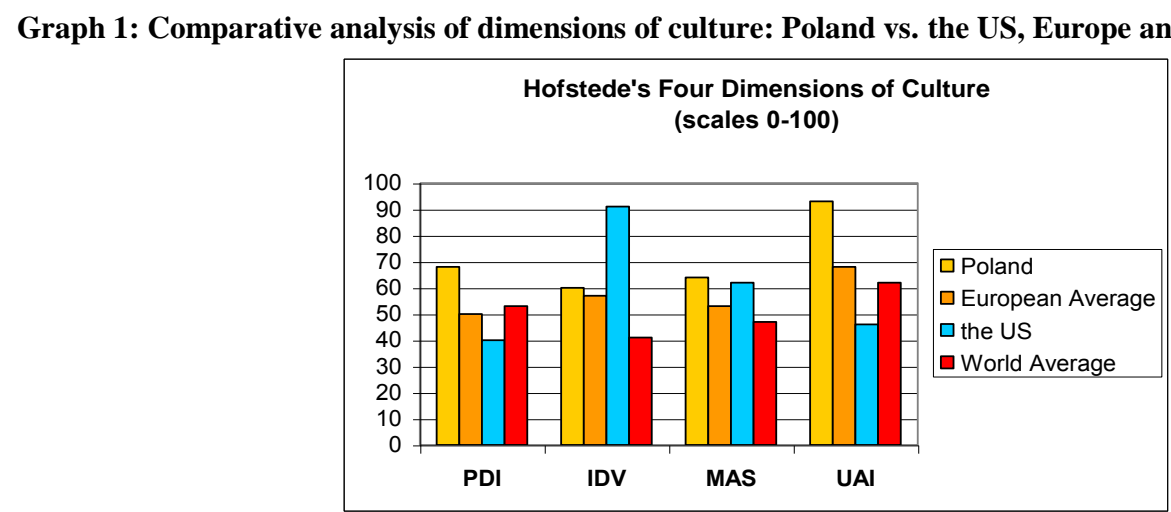

Source: compiled on the basis of http://www.geert-hofstede.com

Graph 1 presents a comparative view of PD, IDV, MAS and UAI of Poland, Europe, the US and the World where nominal values of the indices are used. Only the scores of the countries for which the values have been calculated by Hofstede are presented. LTO is not included in our graph because it would be impossible to aggregate it the same way the calculations have been done for the other dimensions (only 28 countries/regions have their LTO listed). The comparison shows that Poland indeed has higher values than the three other entities, except for the US which is the most individualistic country in the world.

The situation changes but only vis-à-vis relative differences when the indices are weighted by the population sizes of the respective countries and aggregates. Poland still stands out as a country with above average values for PDI, MAS and UAI.

Graph 2: A comparative view of Hofstede's cultural dimensions: Poland vs. European Average, the US and the World Average. Dimensions indices are weighted by the respective populations of the aggregates, i.e.,

Europe, the US and the World

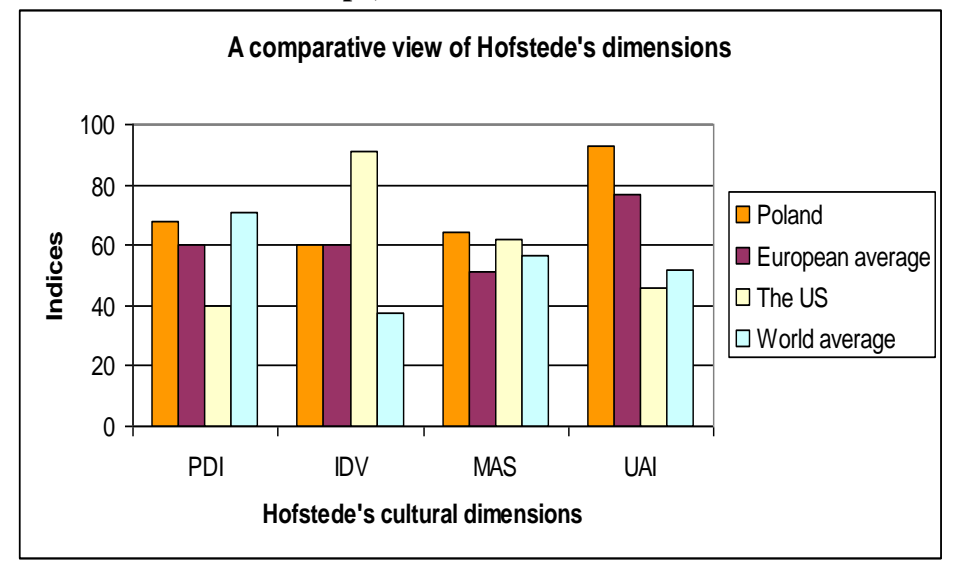

Source: own compilation on the basis of http://www.geert-hofstede.com and United Nations Statistics Division, Demographic and Social Statistics, available at:

http://unstats.un.org/unsd/demographic/products/dyb/dyb2.htm, accessed December 2007 
On the bases of all the premises mentioned above we speculated that:

H3: the majority of respondents will find Power Distance the most irritating feature experienced at workplace in Poland (they will point out in Q3 (workplace) statements related to Power Distance, i.e., the answers they will choose will mostly fall into the category of PD),

and

H4: the majority of respondents will find Power Distance the most irritating feature experienced at social space in Poland (they will point out in Q4 (public place) statements related to Power Distance, i.e., the answers they will choose will mostly fall into the category of PD).

Questions 3 and 4 mirror Hypotheses 3 and 4: "Please, tick the box which corresponds to the feature irritating you MOST in professional interaction in Poland" and "Please, tick the box which corresponds to the feature irritating you MOST in community/social/public space in Poland" (see the Attachment).

\section{DESCRIPTION OF THE STUDY}

\section{Sample}

In order to test our hypotheses, we targeted a specific type of mobile human capital, the so-called expatriate specialists (understood as employees undergoing an intra-organisational geographical transfer across national borders), similarly to the various researchers listed in the Literature review section. The country we chose as the "foreign cultural environment" (i.e., an environment which is responsible for producing culture shock to the people submerged in it) is Poland. This type of respondent is burdened with limitations although there are studies which do not differentiate between migrants and expatriates (e.g., Pires, Stanton and Ostenfeld, 2006). Following the path carved by the majority of research and business practice (especially Human Resources) devoted to expatriate managers, we also chose them as targets because of the following advantages: such people are easy to reach, computer literate, opinion forming (most of the respondents are in the senior managerial capacity) and English speaking. However we are aware that they are "human capital" rather than migrant labour force (as specified e.g., by Massey et al., 1993).

The sample in our study - in addition to representing this special kind of mobile human capital - was a purposive sample, in the sense that sample collection methodology had this particular type of respondent in mind. The target respondents were: expatriate executives and/or their spouses, business people, diplomats and TEFL teachers in Poland. They had to fulfill two basic conditions: be present (living, not visiting) in Poland and be "genuine" expatriates. We defined a "genuine" expatriate as somebody who was born and bred in a country other than Poland.

In order to isolate a sample qualified according to these criteria, we included the following questions in the questionnaire: Question 1: What is your nationality/country of national origin? Please, choose from the options (a drop-down list of countries), and Question 36 (the last question): What was your nationality at birth/country of birth (if different from 1)? (See Attachment). The conditions of the test were controlled in the sense that all potential respondents had to fulfill two conditions: be 'genuine' expatriates and be currently resident in Poland. 'Fake' expatriates (usually those born in Poland who later emigrated to another country) could thus be disqualified (by comparing their answers to Questions 1 and 36).

A plea for respondents was placed on the British Polish Chamber of Commerce website, in the American Friends of Warsaw Newsletter, on a couple of Internet professional discussion fora, in various "expatriate letter chains and circles" and using the authors' own personal networks. Each respondent was guaranteed anonymity yet each is identifiable to the researchers (there is a rigour of Confidentiality Clause). Only self-selecting voluntary respondents were accepted, i.e., they had to respond to the plea via a direct e-mail letter to the authors and declare their willingness to participate in the study. Only then would they be sent a copy of the questionnaire and a confidentiality clause. 


\section{Additional Assumptions}

Before we started to design the questionnaire, we had to consider a few methodological questions, in addition to the assumptions which we defined in the summary of literature review, i.e., those drawn from the theory as indicated at the beginning of this paper (such as that everybody in a migration situation goes through culture shock, as mentioned earlier.)

These additional assumptions have underlain the Project rationale:

political correctness and other outside pressure (sometimes internalized) will distort the results. That is why we decided to accept only self-selected respondents (who by volunteering to participate in the study indicated their awareness of the issue). A special design of the questionnaire (i.e., the one option forced answer in Questions 3 and 4, and no possibility to include "mitigating" comments) further addressed this bias;

precisely the same reason (i.e., being aware of how political correctness could affect the results) stopped us from including The Masculinity/Femininity in the statement set in Q3 (relating to workplace). We thought that if we included MAS coded statement(s) referring to workplace in Q3 (which could be understood as indicating sexual harassment) we would receive blatantly obvious results. Therefore we decided to avoid the issue altogether, leaving it for other researchers and (possible) further studies. To counterbalance the odd number of cultural dimensions in Q3 we decided to include Long Term Orientation there (although Poland is only one out of 28/regions countries for which this the measure had been done). In contrast to Q3, we did include MAS in Q4, i.e., the public place (and omitted LTO);

(iii) the psychological costs of culture shock expressed through the feelings of irritation is a given;

(iv) all the 'irritants' have been listed, i.e., included in the questionnaire's Question 3 and 4. If there is an "irritant" which has not been addressed in Question 3 and 4, it must be ignored;

(v) respondents are classed by their nationalities. Their nationalities are represented by their culture's aggregate measures for cultural dimensions. We used this premise (in spite of its - unavoidable - bias) among others - while we calculated the cultural dimensions indices weighted by the (summed up) populations sizes of the respective countries and aggregates in Graph 2, and

(vi) one answer (predetermined=forced, but subjectively picked) in each area is the researchers' conscious choice - the assumption being that respondents will act on an impulse and the 'one answer only' strategy will reflect their 'gut reaction'.

\section{Questionnaire}

A questionnaire was developed for studying the hypotheses listed above. The questionnaire was developed as a result of several brainstorming sessions with expatriates whose stay in Poland. The questionnaire was pre-tested with six individuals ("genuine" expatriates) and two Information Technology specialists. As a result of the pilot studies the questionnaire was revised to improve the technical, lexical and stylistic content. The tool was a html survey with 36 questions in total (see Attachment). The study was carried out between April and October 2006. The statements in Questions 3 and 4 were coded and scrambled. They corresponded to cultural dimensions defined by Hofstede: Power Distance, Individualism, Uncertainty Avoidance, Masculinity and Long Term Orientation. The statements had been compiled in a series of brain storming sessions and discussed and edited by two individuals (who would otherwise qualify as target respondents). They were written in everyday English and they mimicked verbal expressions of irritation at certain behavior (e.g., "I am tired of all the excuses my Polish employees/colleagues give me as to why something hasn't been done" (Q3); "Aggressive drivers in Poland drive me mad" (Q4) - as explained earlier. The answer (one for each question) to Questions 3 and 4, respectively, was a one forced choice out of 15 statements (See Attachment). If the respondent hit one answer in Q3 and Q4, the other choices became inactive. Of course, they could change their mind re: the one choice in Q3 and Q4, but the technical application would not allow them to mark more than one statement. After the respondents completed the questionnaire, it condensed itself to eight short answers: a name of the country, yes/no, one choice in Q3, one choice in Q4, five answers to the questions on the respondents' statistical information (coded as numbers) and again the name of the country. At the bottom of the answer sheet was the e-mail address of one of us which the respondents just had to hit and it ended up in our e-mail boxes. 


\section{The Respondents}

Below is the basic analysis of the respondents' background. In order to elucidate the general "expatriate" situation (foreigners working in Poland legally, i.e., having a work permit), we have decided to insert the data on foreign workers in Poland as of December 31, 2004: 1,625 women and 6,048 men (GUS http://www.stat.gov.pl/dane_spol-gosp/praca_ludnosc/pracujacy/pra2005.pdf, accessed Dec. 2006).

Additionally, below is the information on the industries in which they were employed.

Graph 3: Foreigners employed in Poland in 2004 by industries

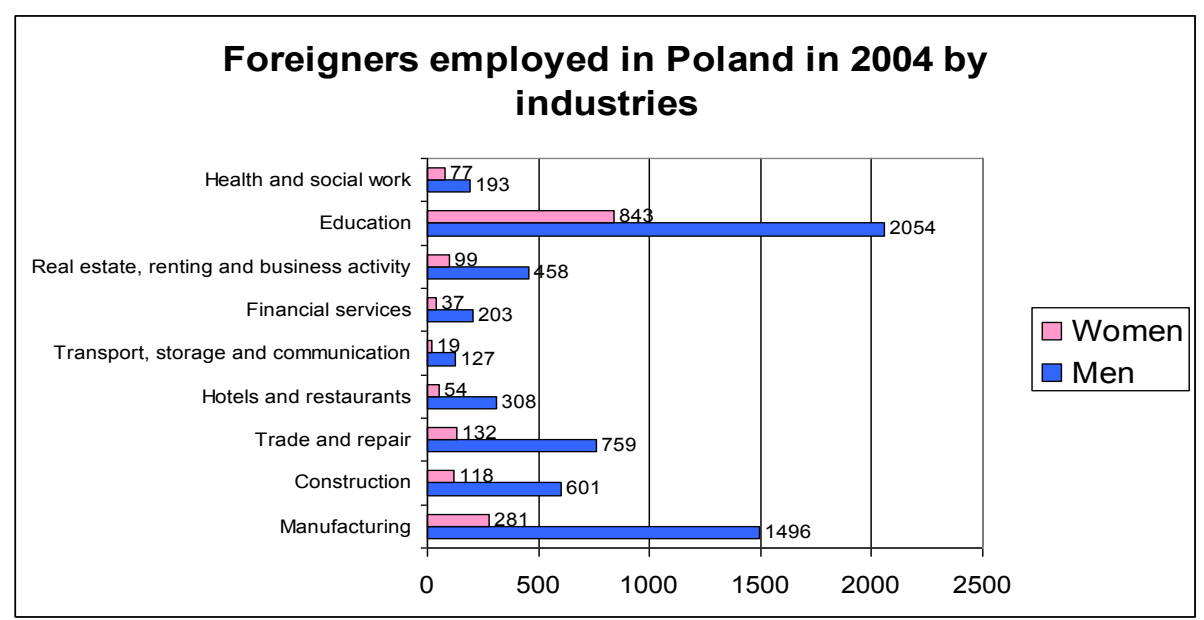

Source: GUS http://www.stat.gov.pl/dane_spol-gosp/praca_ludnosc/pracujacy/pra2005.pdf, accessed Dec. 2006

Fifty seven individuals were qualified as respondents in the study. This number roughly represents $0.75 \%$ of the total number of foreigners employed in Poland as of Dec. 31, 2004 (legally) at more or less similar period to the time when the study was conducted (2006). There were 50 men and 7 women in the sample. Additional information on the respondents can be summarized as follows:

- $\quad$ nationality: US (16), UK (26), Ireland (5), India (2), France (2), Belgium (1), Norway (1), South Africa (1), Canada (1), New Zealand (1), Belarus (1). Thus, 49 out of 57 were of Anglo-Saxon origin, which corresponds to $86 \%$. It is not surprising in view of the sample gathering method;

- $\quad$ age: under 39 (12), 40-49 (11), 50-59 (19) and 60+ (15);

- $\quad$ education (years of formal schooling): max. 15 years (16), 16-17 years (17) and 18 or over years (24);

- $\quad$ occupation (the classification had been invented by Hofstede and made accessible to all researchers wishing to apply it): No paid job (includes full-time students), Unskilled or semi-skilled manual worker, Generally trained office worker or secretary, Vocationally trained craftsperson, technician, informatician, nurse, artist or equivalent, Academically trained professional or equivalent (but not a manager of people), Manager of one or more subordinates (non-managers), Manager of one or more managers. We aggregated the above groups of occupations into three categories: senior manager (28), junior manager (11) and employee (18).

\section{ANALYSIS AND RESULTS}

The aggregation of the socio-demographic variables was done for the purpose of conducting statistical analyses, particularly cross-tabulations.

With respect to being sick while abroad (H1), we used the z statistic to test the null hypothesis that the proportion of respondents who did not notice they were sick (physically) in Poland more, is 50\%. We rejected this 
hypothesis decisively $(\mathrm{p}=.000)$ against the alternative hypothesis that such the proportion is greater than $50 \%$. In our sample, we actually observed that more than three quarters (77.2 per cent) of respondents stated they did not notice they were sick (physically) in Poland more. Thus, our hypothesis H1 could not be confirmed.

Additionally, no statistically significant relations were found between being prone to be sick more often (physically) while in Poland and the age of the our respondents as standard statistical testing for $\mathrm{H} 2$ proved there was no association (the p-value for the corresponding chi-square test was more than .05). Thus $\mathrm{H} 2$ has been validated.

The hypothesis H3 has not been validated (see Table 1). However, more than one third (35.1\%) of the respondents pointed out (large) Power Distance as one of the two most irritating features at workplace. The dimension pointed out the most frequently was Uncertainty Avoidance (by 45.6\%). It is true that Poland scores significantly higher (93) than all the countries which the respondents come from - except for Belgium (one respondent) which scores 94 and France (two respondents) which scores 86 (i.e., close to Poland's score). Such a result would contradict Hofstede's claim that Power Distance takes precedence over Uncertainty Avoidance. The other explanation for such a result may be the size (small) and a dense cultural homogeneity of the sample (86\% were of Anglo-Saxon origin). The implications for future research therefore would be to consider Q3 in view of the national spread of the future sample or indeed re-formulate the hypothesis by combing PDI and UAI as a compound variable.

Table 1: Breakdown of the answers to Q. 3 (Irritation while at work place)

\begin{tabular}{|l|l|c|c|c|c|}
\hline \multicolumn{9}{|c|}{ Iwpcode } \\
\hline \multirow{3}{*}{ Valid } & & Frequency & Percent & Valid Percent & Cumulative Percent \\
\cline { 2 - 7 } & PowerDistanceWP & 20 & 35.1 & 35.1 & 35.1 \\
\cline { 2 - 7 } & UncertaintyAvoidWP & 26 & 45.6 & 45.6 & 80.7 \\
\cline { 2 - 7 } & IndividualismWP & 7 & 12.3 & 12.3 & 93.0 \\
\cline { 2 - 7 } & LongTermOrientWP & 4 & 7.0 & 7.0 & 100.0 \\
\cline { 2 - 7 } & Total & 57 & 100.0 & 100.0 & \\
\hline
\end{tabular}

Upon examination of responses to "irritation at public places", the majority (75.4\%) indicated Power Distance (see Table 2).

Thus H4 has been validated. It is interesting that so many people pointed out Power Distance as a feature impeding smooth functioning in public space in Poland. In our study, Uncertainty Avoidance, together with Masculinity scored less at public places. Individualism (7 replies) is the second most irritating dimension listed by the respondents. It is worth considering why Uncertainty Avoidance scores so highly on the irritation scale at workplace, but its role diminishes in public places. Our original speculation was that large Power Distance (which can also be perceived as a possible legacy from communism) may have an exceptional, comprehensive and profound influence in Poland, in all areas - from management to client service. The results of this study may indicate that Power Distance, Uncertainty Avoidance as well as the two dimensions in combination need to be investigated in our further studies regarding Poland.

Table 2: Breakdown of the answers to Q. 4 (Irritation while at public places)

\begin{tabular}{|c|c|c|c|c|c|}
\hline \multicolumn{6}{|c|}{ Ippcode } \\
\hline & & Frequency & Percent & Valid Percent & Cumulative Percent \\
\hline \multirow[t]{5}{*}{ Valid } & PowerDistancePP & 43 & 75.4 & 75.4 & 75.4 \\
\hline & UncertaintyAvoidPP & 4 & 7.0 & 7.0 & 82.5 \\
\hline & IndividualismPP & 7 & 12.3 & 12.3 & 94.7 \\
\hline & Masculinity_FemininityPP & 3 & 5.3 & 5.3 & 100.0 \\
\hline & Total & 57 & 100.0 & 100.0 & \\
\hline
\end{tabular}




\section{CONCLUSIONS, LIMITATIONS, AND RECOMMENDATIONS FOR FURTHER RESEARCH}

The evidence towards validation of Hypothesis 1 is not sufficient. A socio-demographic feature, such as age appears to have no further influence. Further tests are necessary to investigate H1 (as specified in the Recommendations for further study section). Yet, in all fairness, we cannot assume that we have a base solid enough to speculate about people's proneness to physical sickness while abroad. Cross-tabulation tests have proven that younger people (in this sample) are not more vulnerable to physical sickness (which could be attributed to culture shock). $\mathrm{H} 2$ has therefore been confirmed.

Hypothesis 3 has not been validated, but Power Distance did feature as the second most outstanding feature. Hypothesis 4 has been validated and the results have provided enough information to state that Power Distance is a critical area for expatriates in Poland, either on its own or as part of the PDI/UAI tandem. As hypothesized, Power Distance did indeed emerge as a second most problematic area at work (where expatriates meet Poles). The first most frequently indicated dimension was Uncertainty Avoidance. In the community/social/public space the features which have been most frequently indicated by the respondents is Power Distance. Standard statistical methods (cross-tabulations) have demonstrated that no demographic or social feature (sex, age, education, job, nationality) correlate with Q3 and Q4 choices.

We are aware that the sample is biased: it is a purposive sample. More general conclusions cannot be extrapolated from this stage of the research. However, one of the limitations (a relative homogeneity of the sample) has given us ideas for further tests (such as conducting another test on a German sample and an 'obverse' study on Polish migrants, as mentioned below), which, in turn, could also produce some unexpected and yet valuable results.

We also realize that women are under-represented, although the distribution in the gender in the study correctly reflects the structure of the foreign labor market (foreigners working in Poland). That is why further and more detailed analysis as per gender specific observations are not allowed in the present study. Nevertheless, it would be interesting to compare the answers from a more heterogeneous sample, particularly vis-à-vis the Masculinity/Femininity dimension. This issue may be worth designing a separate questionnaire for.

Another issue which calls for improvement is statement coding. In this paper, it was intuitive rather than empirically verified. Future questionnaire design will require more field work and more pilot tests.

The fact that the dimensions were not equally represented by the number of statements could also be remedied by more field work, more brain storming sessions, and more pilot tests. The sample is rather small and therefore the results may only serve as the basis for further studies, as described below. In order to test the strength of the validity of $\mathrm{H} 3$ and $\mathrm{H} 4$, an identical study should be conducted on a sample of German expatriates (who are represented numerously) in Poland, and/or possibly another (non-Anglo-Saxon) nationality (or a few nationalities combined). The questionnaire (modified by the exclusion of Hypothesis 1 and 2, but an inclusion of a hypothesis on the role of Uncertainty Avoidance and a possible hypothesis on the role of the two dimensions combined) should be translated into the respondents' corresponding native tongues. It will be very interesting to see which out of the two critical areas: Power Distance or Uncertainty Avoidance (and also their role in combination) would be pointed out as by respondents from a sample consisting from people from yet another culture. The idea is that they would identify those outstanding feature(s) of the Polish culture which makes their life at work and in public places in Poland difficult. The results of this and the future studies could create an interesting venue for further research as well as for practitioners and policy makers. On the managerial level, practical solutions to the Power Distance cum Uncertainty Avoidance dilemma could be offered in terms of the special design and the content of the courses for expatriate managers assigned to Poland (e.g., induction programs). On the other hand, the results may create the need to enrich in-company training courses for Polish managers to specifically identify, address and rectify these sources of inefficiency in accordance with the Western managerial practices. The results of our study may, additionally, shed light on the effectiveness of adopting managerial solutions, job organization, and employer expectations of subordinates in Poland and corroborate - or not - the results of the Godden (2004) study. On the other hand, émigré Poles who left Poland (especially after May 1, 2004) and are working abroad could be tested for their perception of Power Distance and Uncertainty Avoidance in their respective host countries. It would be a sort of "obverse" study to the one described here. Such a study would demand a completely different design of a questionnaire, but - in 
contrast to the study described here - could probably rely on a larger and less purposefully selected sample. The sample would also be different in the sense which Massey et al. (1993) had meant: more of a labor flow rather than international human capital flow. Naturally, a great deal of field work, preparation and pre-research testing is necessary in such a study.

The results of this study (and the studies proposed to follow the present study) could have implications for several parties involved, including cross-cultural managers and policy makers in sending (e.g., Poland) and receiving countries (e.g., the UK, Ireland, US) respectively. The managerial implications are rich and not only for cross-cultural managers. It is possible that high values of Power Distance (and Power Distance in combination with Uncertainty Avoidance) have an important role in shaping leadership in Poland - in various fields. This area - if explored further - could provide more information on how to improve performance and help diminish the gap between Poland and other regions in the world.

\section{NOTES}

$\mathrm{i}$ "Evidence that psychological stress or discomfort is extant during acculturation is widespread, although the level is dependent on specific local circumstances (...)" (Berry and Anis, 1974, p. 383).

ii "Whether we use unadjusted or adjusted citations, Dunning, Porter, Vernon, Casson, Rugman, and Hofstede have had the greatest influence on international business research during the period 1984-1993" (Chandy, 1994, p. 727).

"The classic work of Hofstede (1980) has revolutionized the research on culture and IB. (...) The validity of the cultural dimensions identified by Hofstede has been controversial (...), but they have provided a broad framework that has inspired much IB research. (Leung et al., 2005, p. 365).

\section{AUTHOR INFORMATION}

Anna Murdoch is an Adjunct Professor at Warsaw School of Economics, Warsaw, Poland. She earned her BA at Thames Valley University, London, England, her MA at Warsaw University, Warsaw, Poland, and her PhD in the field of Economic Sciences at Warsaw School of Economics (1998). She is the author of seven books and co-author of two. She has published articles in Journal of Intercultural Management, European Business Forum and various Polish scientific journals.

Eugene Kaciak is an Associate Professor of Management at Brock University in St. Catharines, Ontario, Canada. He earned both his M.Sc. in Economics (1973) in the field of Management Science and his PhD in the field of Econometrics (1977) at Warsaw School of Economics (Poland). He published articles in a number of scientific journals, including Journal of Marketing Research, Advances in Consumer Research, Journal of Developmental Entrepreneurship, Journal of International Consumer Marketing, Journal of Targeting, Measurement and Analysis for Marketing, International Business \& Economics Research Journal, Journal of Microcomputer Applications, and Revue Internationale PME.

\section{REFERENCES}

1. Adler, P. S., The Transitional Experience: An Alternative View of Culture Shock, Journal of Humanistic Psychology, Vol. 15, No. 4, pp. 13-23, 1975.

2. Ang, S., van Dyne, L. and Koh, C., Personality Correlates of the Four-Factor Model of Cultural Intelligence, Group Organization Management, Vol. 31, pp. 100-123, 2006.

3. Arthur N. Counseling International Students: Clients from Around the World, Kluwer Academic, New York, 2004.

4. Aycan, Z. Expatriate adjustment as a multifaceted phenomenon: individual and organizational predictors, The International Journal of Human Resource Management, Vol. 8, No. 4, pp. 434-56, 1997.

5. $\quad$ Berne, E., Games People Play, Random House Inc., London, 1964.

6. $\quad$ Berry, J. W., \& Annis, R. C., Acculturative stress, Journal of Cross-Cultural Psychology, Vol. 5, pp. 382406, 1974.

7. Berry, J. W., Kim, U., Minde, T., and Mok, D., Comparative studies of acculturative stress, International Migration Review, Special Issue: Migration and Health, Vol. 21, No. 3, pp. 491-511, 1987. 
8. Berry, J. W., Poortinga, Y. H., Segall, M. H. and Dasen, P. R. Cross-cultural Psychology. Research and Application, Cambridge University Press, Cambridge, 1992.

9. Birdseye, M. G., Hill J. S., Individual, Organizational/Work and Environmental Influences on Expatriate Turnover Tendencies: An Empirical Study, Journal of International Business Studies Vol. 26, pp. 787-813, 1995.

10. Black, J. S. and Mendenhall, M., Cross-Cultural Training Effectiveness: A Review and a Theoretical Framework for Future Research, The Academy of Management Review, Vol. 15, No. 1, pp. 113-136, 1990.

11. Black, J. S., Mendenhall, M. E., Oddou, G. (1991) Toward a comprehensive model of international adjustment: an integration of multiple theoretical perspectives, Academy of Management Review, 16(2), 291-317.

12. Black, J. S., \& Mendenhall, M. E. (1991) The U-Curve Adjustment Hypothesis Revisited: A Review and Theoretical Framework, Journal of International Business Studies, 22(2), 225-247.

13. Black, J. S. and Stephens, G.K. (1989) The influence of the spouse on American expatriate adjustment and intent to stay in Pacific Rim overseas assignments, Journal of Management, 15(4), 529-44.

14. Bolino, M. C. (2000) Skill utilization and underemployment among expatriates: a relative deprivation approach, a doctoral dissertation, pp. 1-322, 2000, available at: http://proquest.umi.com/pqdweb?index $=0 \&$ sid=1\&srchmode=2\&vinst=PROD\&fmt=6\&startpage=$1 \&$ clientid=46580\&vname=PQD\&RQT=309\&did=727714881\&scaling=FULL\&ts=1211705094\&vtype=P QD\&rqt=309\&TS=1211705104\&clientId=46580 Accessed 23 July, 2008.

15. Bolino, M. C. and Feldman D. C., The Antecedents and Consequences of Underemployment among Expatriates, Journal of Organizational Behavior, Vol. 21, No. 8, pp. 889-911, 2000.

16. Chandy P. R., Williams, T. G. E., The impact of journals and authors on international business research: a citational analysis of JIBS articles, Journal of International Business Studies, Vol. 25, No. 4, pp. 715-728, 1994.

17. Chin, H. K. Open doors: Report on international education exchange, Institute of International Education, New York, 2002.

18. Church, A. T., Sojourner Adjustment, Psychological Bulletin, Vol. 91, No. 3, pp. 540-572, 1982.

19. Clark Oropeza, B. A., Fitzgibbon, M., \& Baron, A., Managing mental health crises of foreign college students. Journal of Counseling and Development, Vol. 69, pp. 280-284, 1991.

20. Crano, S. L., Crano W. D. A measure of adjustment strain in international students, Journal of CrossCultural Psychology, Vol. 24, pp. 267-283, 1993.

21. Deen, N., (Young) Newcomers in European societies: Implications for education and counseling, International Journal for the Advancement of Counseling, Vol. 24, pp. 3-17, 2002.

22. Dicks, D., Cupid's Wild Arrows. Intercultural Romance and Its Consequences, Bergli Books Ltd., Weggis, 1993.

23. Feichtinger, C., Fink G., The collective culture shock in transition countries - theoretical and empirical implications, Leadership \& Organization Development Journal, Vol. 19, No. 6, pp. 302-309, 1998.

24. Feldman, D. C., Leana C. R. and Bolino M. C., Underemployment and relative deprivation among reemployed executives, Journal of Occupational and Organizational Psychology, Vol. 75, pp. 453-471, 2002.

25. Furnham, A. and Bochner, S., Cultural shock: Psychological reactions to unfamiliar environments, New York: Methuen \& Co, New York, 1986.

26. Gooden, D. J. An examination of national culture and transformational leaders' practices across four countries, ProQuest Dissertations and Theses; 2003.

27. Gudykunst, W. B. and Hammer, M. R., Strangers and hosts - an uncertainty reduction based theory of intercultural adaptation, pp. 106-139, in: Kim, Y. Y. and Gudykunst, W. B. (Eds), Cross-Cultural Adaptation - Current Approaches, Sage Publications, Newbury Park, CA, 1988.

28. Gullahorn, J. T., \& Gullahorn, J. E., An extension of the U-curve hypothesis, The Journal of Social Issues, Vol. 19, No. 3, pp. 33-47, 1963.

29. Harzing, A. W. K., The persistent myth of high expatriate failure rates, International Journal of Human Resource Management, Vol. 6, No. 2, pp. 457-474, 1995.

30. Haslberger, A., Facets and dimensions of cross-cultural adaptation: refining the tools, Personnel Review, Vol. 34, No. 1, pp. 85-109, 2005a. 
31. Haslberger, A., The complexities of expatriate adaptation, Human Resource Management Review Vol. 15, pp. 160-180, 2005b.

32. Haslberger, A., Brewster C., Towards a Taxonomy of Expatriate Adjustment, paper presented at the IV International Conference of Iberoamerican Academy of Management, (December), Lisbon, 2005.

33. Hofstede, G., Culture's consequences. International Differences in Work-Related Values, Sage, Newbury Park, 1980.

34. Hofstede, G., Culture's consequences. International Differences in Work-Related Values, Sage, Newbury Park, 1984.

35. House, R., Hanges, P., Javidan, M., Dorfman, P. and Gupta, V. (Eds), Culture, leadership, and organizations: The GLOBE study of 62 societies, Sage Publications, Thousand Oaks, CA, 2004.

36. Giuliani, I., Università Commerciale Luigi Bocconi di Milano, Una fase critica dell'expatriate management: il rientro, a $\mathrm{PhD}$ thesis, pp. 1-175 (2003-04) available at: http://www.tesionline.com/intl/thesis.jsp?idt=11496, accessed 23 July 2008.

37. Guy, B. S., Patton W. E., Managing the effects of culture shock and sojourner adjustment on the expatriate industrial sales force, Industrial Marketing Management Vol. 25, pp. 385- 393, 1996.

38. Janssens, M., Intercultural Interaction: A Burden on International Managers? Journal of Organizational Behavior, Vol. 16, No. 2, pp. 155-167, 1995.

39. Kealey, D. J., A study of cross-cultural effectiveness: theoretical issues, practical applications, International Journal of Intercultural Relations, 13, pp. 387-428, 1989.

40. Klos Sokol, L., Shortcuts to Poland, IPS, Warsaw, 1996.

41. Kohls, R. L., Survival Kit for Overseas Living, Intercultural Press, Inc, Yarmouth, 1984.

42. Kohls, R. L. and Knight J. M., Developing Cultural Awareness. A Cross-Cultural Training Handbook, Intercultural Press, Inc. Yarmouth, 1994.

43. Kolman, L., Noorderhaven, N.G., Hofstede, G. and Dienes, E., Cross-cultural differences in Central Europe, Journal of Managerial Psychology, Vol. 18 No. 1, pp. 76-89, 2003.

44. LeDoux, J., Synaptic Self-How Our Brains Become Who We Are, Viking Penguin, New York, NY, 2002.

45. LeDoux, J., Emotion: clues from the brain, Annual Review of Psychology, Vol. 46, pp. 209-35, 1995.

46. Leung, K. et al., Culture and international business: recent advances and their implications for future research, Journal of International Business Studies Vol. 36, pp. 357-378, 2005.

47. Lewis, T. J., Jungman, R. E., (eds.), On Being Foreign. Culture Shock in Short Fiction. An International Anthology, Intercultural Press, Yarmouth, 1986.

48. Lewthwaite, M., A study of international students' perspectives on cross-cultural adaptation, International Journal for the Advancement of Counseling Vol. 19, pp. 167-185, 1996.

49. Lin, Y., Cultural implications of self-other agreement in multi-source feedback: comparing samples from U.S., China, and globally dispersed teams. A PhD dissertation, 2007, available at: http://digital.library.unt.edu/permalink/meta-dc-3947:1, accessed 23 July, 2008.

50. Littrell, L., Salas, E., Hess, K. P., Paley, M., Riedel, S., Expatriate Preparation: A Critical Analysis of 25 Years of Cross-Cultural Training Research, Human Resource Development Review, Vol. 5, No. 3, pp. 355388, 2006.

51. Live and Work Abroad. The Expatriate Experience, (a handbook), GMAC Global Relocation Services, London, 2001.

52. Lysgaard, S., Adjustment in a foreign society: Norwegian Fulbright grantees visiting the United States, International Social Science Bulletin, Vol. 7, pp. 45-51, 1955.

53. Massey, D. S., Arango, J., Hugo, G., Kouaouci, A., Pellegrino, A. and Taylor, J. E., Theories of International Migration: Review and Appraisal, Population and Development Review, Vol. 19, No. 3, pp. 431-466, 1993.

54. Mendenhall, M., \& Oddou, G., The dimensions of expatriate acculturation: A review, Academy of Management Review, Vol. 10, pp. 39-47, 1985.

55. Mendenhall, M., \& Oddou, G., Acculturation profiles of expatriate managers: Implications for crosscultural training programs, Columbia Journal of World Business, Vol. 21, pp. 73-79, 1986.

56. Mendenhall, M., \& Oddou, G., The Overseas Assignment: A Practical Look. Business Horizons, Vol. 31, No. 5, pp. 78-84, 1988. 
57. Merta, R. J., Stringham, E. M, Ponterotto, J. G., Simulating Culture Shock in Counselor Trainees: An Experiential Exercise for Cross-Cultural Training, Journal of Counseling and Development, Vol. 66, No. 5, pp. 242-245, 1988.

58. Mol, T., Crossing Borders with Personnel Selection: from Expatriates to Multicultural Teams, PhD dissertation Erasmus University Rotterdam, a $\mathrm{PhD}$ dissertation, 2007, available at: http://publishing.eur.nl/ir/repub/asset/10757/Dissertation\%20Stefan\%20T.\%20Mol\%20\%20Crossing\%20Borders\%20with\%20Personnel.pdf, 2007, accessed 23 July, 2008.

59. Murdoch, A., Wspótpraca z cudzoziemcami w firmie (Working Together with Foreigners) Poltext, Warsaw, 1999.

60. Murdoch, A., How much culture is there in corruption? Some thoughts on transformation-cum-collective culture shock in post-communist Poland, Journal of Intercultural Management, Vol. 1, No. 1, pp. 42-63, 2009.

61. Murdoch, A., Some Costs of Culture Shock in the Process of Human Capital Adaptation during Temporary Migration, paper presented at the AIB 2007 Annual Meeting, (June) Indianapolis, US, 2007.

62. Nasierowski, W. and Mikula, B., Culture dimensions of Polish managers: Hofstede's indices, Organisation Studies, Vol. 19 No. 3, pp. 495-510, 1998.

63. Ng E. S. W., Leadership-Based Theoretical Framework. Why Organizations Choose to Manage Diversity? Human Resource Development Review, Vol. 7, No. 1, pp. 58-78, 2008.

64. Novicevic, M. M., Harvey, M., The changing role of the corporate HR function in global organizations of the twenty-first century, International Journal of Human Resource Management, Vol. 12, No. 8, pp. 12511268, 2001.

65. Oberg, K., Cultural shock: adjustment to new cultural environments, Practical Anthropology, Vol. 7, pp. 177-82, 1960.

66. Pandeliou, S. and Craig, T. K. J., Culture shock and social support. A survey in Greek migrant students, Social Psychiatry and Psychiatric Epidemiology, Vol. 41, pp. 777-781, 2006.

67. Parker, S., Kleiner R. J. and Needelman, B., Migration and mental illness. Some reconsiderations and suggestions for further analysis, Social Science and Medicine, Vol. 3, pp. 1-9, 1969.

68. Pires, G., Stanton, J. and Ostenfeld, S., Improving expatriate adjustment and effectiveness in ethnically diverse countries: marketing insights, Cross Cultural Management: An International Journal, Vol. 13, No. 2, pp. 156-170, 2006.

69. Popadiuk, N. and Arthur, N., Counseling International Students in Canadian Schools, International Journal for the Advancement of Counselling, Vol. 26, No. 2, pp. 125-145, 2004.

70. Sappinen, J., Expatriate Adjustment on Foreign Assignment, European Business Review, Vol. 93, No. 5, pp. 3-11, 1993.

71. Schwartz, S. H., Beyond Individualism/Collectivism: New Dimensions of Values. Individualism and Collectivism: Theory application and methods, in: Kim U., H. C. Triandis, C. Kagitçibasi, S. C. Choi and G. Yoon (Eds), Individualism and Collectivism: Theory, Method, and Applications, Sage, Newbury Park, CA, pp. 85-119, 1994.

72. Searle, W., \& Ward, C., The prediction of psychological and sociocultural adjustment during cross-cultural transitions, International Journal of Intercultural Relations, Vol. 14, pp. 449-464, 1990.

73. Shaffer, M. A., Harrison, D. A., Gilley, K. M., Dimensions, Determinants, and Differences in the Expatriate Adjustment Process, Journal of International Business Studies, Vol. 30, No. 3, pp. 557-581, 1999.

74. Sussman, N. M., The Dynamic Nature of Cultural Identity Throughout Cultural Transitions: Why Home Is Not So Sweet, Personality and Social Psychology Review, Vol. 4, pp. 355- 373, 2000.

75. Takeuchi, R., Wang, M., Marinova, S. V., Antecedents and consequences of psychological workplace strain during expatriation: a cross-sectional and longitudinal investigation, Personnel Psychology, Vol. 58, No. 4, pp. 925-948, 2005.

76. Takeuchi, R., Yun, S., \& Tesluk, P. E., An examination of crossover and spillover effects of spousal and expatriate cross-cultural adjustment on expatriate outcomes, Journal of Applied Psychology, Vol. 87, pp. 655-666, 2002.

77. Ten Years of Global Relocation Trends: 1993-2004, GMAC Global Relocation Services, London, 2004.

78. Thomas, A. (ed.) Kulturvergleichende Psychologie, Hogrefe, Gottingen, 1993. 
79. Todeva, E. Models for Comparative Analysis of Culture: The Case of Poland. International Journal of Human Resource Management, 10(4), pp. 606-623, 1999.

80. Triandis, H. C., Heron, A. (eds.), Handbook of cross-cultural psychology, vol. 4. Developmental, Allyson \& Bacon, Boston, 1981.

81. Trompenaars, F., Hampden-Turner C., Managing People Across Cultures, Capstone Publishing Ltd, Chichester, 2004.

82. Townsend, P. and Wan, C., The impact of multicultural experience in the development of socio-cultural adaptation for international business students, International Journal of Educational Management, Vol. 21, No. 3, pp. 194-212, 2007.

83. Tung, R. L., Expatriate Assignments: Enhancing Success And Minimizing Failure, The Academy of Management Executive, Vol. 1, No. 2, pp. 117-126, 1987.

84. Tung, R. L., Selection and Training Procedures of U.S., European, and Japanese Multinationals. California Management Review, Vol. 25, No. 1, pp. 57-71, 1982.

85. Tung, R. L., Selection and training of personnel for overseas assignment, Columbia Journal of World Business, Vol. 16, No. 1, pp. 21-25, 1981.

86. Wang, J., Study of Resiliency Characteristics in the Adjustment of International Graduate Students at American Universities, doctoral dissertation, pp. 1-260, 2002, available at: http://etd.lib.fsu.edu/theses/available/etd-09232003-005421/unrestricted/02 jw dissertation.pdf, accessed: 23 July 2008.

87. Ward, C., Leong, C-H., Low, M., Personality and Sojourner Adjustment: An Exploration of the Big Five and the Cultural Fit Proposition, Journal of Cross-Cultural Psychology, Vol. 35, No. 2, pp. 137-151, 2004.

88. Ward, C., Bochner, A., \& Furnham, A., The psychology of culture shock, Taylor \& Francis, Philadelphia, 2001.

89. Zdunczyk, K., Blenkinsopp, J., Do organisational factors support creativity and innovation in Polish firms? European Journal of Innovation Management, Vol. 10, No 1, pp. 25-40, 2007. 


\section{ATTACHMENT: THE QUESTIONNAIRE}

Q1. What is your nationality /country of national origin? Please, choose from the options: (a drop-down list of countries)

Q2. Have you noticed that you've been sick (cold, flu, allergy, others) more frequently since you've arrived in Poland (tick the box)? Yes $\square$ No $\square$

Q3. Please, tick the box which corresponds to the feature irritating you MOST in professional interaction in Poland:

1. Polish employees are ill-at-ease with me (PDI)

2. My Polish employees/colleagues procrastinate too much (UAI)

3. Polish employees don't follow my instructions/orders (PDI)

4. My Polish employees/colleagues only see me as an opportunity for self-gain (IDV)

5. I am tired of being told by my Polish employees/colleagues my way is wrong (IDV)

6. Petty hateful actions/words from my Polish employees/colleagues drive me nuts (IDV)

7. Polish employees always want to be told what to do (PDI)

8. None of my employees/colleagues wants to do anything they won't be paid for (LTO)

9. I am tired of all the foolish excuses why someone cannot come to work (UAI)

10. My Polish employees/colleagues don't tell me if I'm wrong (PDI)

11. I am tired of all the excuses my Polish employees/colleagues give me as to why something hasn't been done (UAI)

12. My Polish employees/co-workers are afraid of me (PDI)

13. I am tired of being told that I should do something the Polish way (IND)

14. I am tired of all the nosiness that surrounds what I'm doing (UAI)

15. I am tired of my Polish employees/colleagues' silly excuses as to why they're late (UAI)

Q4. Please, tick the box which corresponds to the feature irritating you MOST in community/social/public space in Poland:

16. Employees in public institutions/spaces (post office, bank, park) are reluctant to explain the rules (PDI)

17. Waiters and other service professionals are lazy (IDV)

18. I am tired of receiving cold stares/glares from Poles (IDV)

19. Poles are very rude (PDI)

20. Polish women are overly aggressive (MAS)

21. Shop assistants and other service professionals are always angry (IDV)

22. Polish children are allowed to get away with murder (IDV)

23. I don't understand their rules for polite behavior (UAI)

24. Polish men are disloyal (MAS)

25. Aggressive drivers in Poland drive me mad (PDI)

26. Polish people are cliquey (IDV)

27. There is too much bureaucracy (PDI)

28. People in positions of authority are always condescending (PDI)

29. The people I deal with in Poland are so passive (IDV)

30. It is impossible to make monetary change in Poland (UAI)

31. Polish women are manipulative (MAS)

Some information about yourself (for statistical purposes):

32. Are you: (i) male (ii) female

33. How old are you? (i) Under 24; (ii) 25-29; (iii) 30-34; (iv) 35-39; (v) 40-49; (vi) 50-59; (vii) 60 or over

34. How many years of formal school education (or their equivalent) did you complete (starting with primary school)? (i) 10 years or less; (ii) 11 years; (iii) 12 years; (iv) 13 years; (v) 14 years; (vi) 15 years; (vii) 16 years; (viii) 17 years; (ix) 18 years or over

35. What kind of job do you do? (i) No paid job (includes full-time students); (ii) Unskilled or semi-skilled manual worker; (iii) Generally trained office worker or secretary; (iv) Vocationally trained craftsperson, technician, computer scientist, nurse, artist or equivalent; (v) Academically trained professional or equivalent (but not a manager of people); (vi) Manager of one or more subordinates (non-managers); (vii) Manager of one or more managers.

36. What was your nationality at birth/country of birth (if different from 1)? (a drop-down list) 
